\title{
First Fruiting Intergeneric Hybrids between Citrus and Citropsis
}

\author{
Malcolm W. Smith ${ }^{1}$, Debra L. Gultzow, and Toni K. Newman \\ Bundaberg Research Station, Queensland Department of Agriculture, Fisheries and Forestry, \\ 49 Ashfield Road, Bundaberg 4670, Australia
}

\begin{abstract}
Additional Index words. Citrus wakonai, Citropsis gabunensis, conventional hybridization, sexual hybrids, wide-crosses, late-acting lethality

Abstract. Fruiting hybrids are reported for the first time between the genera Citrus L. and Citropsis (Engl.) Swing. \& M.Kell. Conventional hybridization using the recently described species Citrus wakonai P.I.Forst. \& M.W.Sm. and Citropsis gabunensis (Engl.) Swing. \& M.Kell. resulted in high rates of fruit set and seed formation. Although seed were only half normal size, over $\mathbf{9 0 \%}$ germinated without the need for embryo rescue techniques. Plant losses were high during the first few months but after six months, the 327 surviving hybrids were potted on. These grew vigorously on their own roots and 35 of them flowered within two years of sowing. Plants flowered continuously but all were pollen-sterile and ovaries abscised shortly after petal fall. However, at 25 months, two newly flowering hybrids began setting fruit. The development, identification, morphology, breeding efficiency, and future implications of this unique germplasm are described.
\end{abstract}

It is 100 years since the great Walter T. Swingle (Cooper et al., 1962; Tasker, 2010) first attempted to hybridize Citrus and Citropsis (Swingle, 1913). He had established the Citropsis genus (Swingle, 1914) by removing African species from Limonia L. recognizing them as "closely and clearly related to Citrus" and by this time had already envisioned their potential for citriculture and attempted crosses onto Citrus aurantiifolia (Christm.) Swing. However, after a breeding career of more than 50 years, and success in hybridizing a great many other citrus relatives, he concluded that Citrus and Citropsis were sexually incompatible (Swingle, 1945). Many other breeders (e.g., Barrett, 1977; Ford and Peder, 1969; Hutchison, 1976; Iwamasa et al., 1985, 1988) have subsequently attempted this cross, motivated by the useful traits that Citropsis could bring to commercial citriculture, but no hybrid seedlings were obtained. Somatic hybrids between Citrus and Citropsis were first reported by Grosser et al. (1990) and the growth problems exhibited by these initial two hybrids were subsequently overcome by expanding the program to include a greater range of parents (Grosser et al., 1996). Indeed, a 'Nova' mandarin (Citrus reticulata Blanco + Citropsis gilletiana Swing. \& M.Kell.) somatic hybrid has grown with good vigor and shows some promise as a rootstock (Grosser and Chandler, 2003). However, none of these hybrids, or those from other Citrus + Citropsis somatic hybridization programs, have ever flowered despite their considerable age (Grosser and Chandler, 2003; Guo and Deng, 2001; J.W. Grosser, personal communication). The breakthrough came in 2006 when Japanese breeders reported the first intergeneric sexual hybrids between Citrus and Citropsis (Yahata et al., 2006) produced by combining conventional hybridization with embryo rescue and seedling grafting. Although their hybrids

Received for publication 27 Aug. 2012. Accepted for publication 4 Oct. 2012. We thank Robert Krueger and colleagues of the USDA-ARS, Riverside, CA, for provision of germplasm and continued technical input. The assistance of Kerry Bell in providing statistical analysis, Paul Forster in providing botanical advice, and Sam Campbell in image processing is acknowledged. Jude Grosser and Hisato Kunitake are thanked for sharing updated information on related germplasm.

${ }^{1}$ Corresponding author. E-mail: malcolm.smith@daff.qld.gov.au. have been slow-growing and are yet to flower (H. Kunitake, personal communication), they demonstrate a useable level of sexual compatibility between Citrus and Citropsis and were the impetus for renewing our attempts at this cross.

Intergeneric hybridization represents an opportunity to combine genomes from distinctly different plants and to introgress traits not found in the main genus of interest. However, plant groups differ markedly in their crossability with prezygotic and postzygotic barriers to hybridization becoming more severe as the distance between taxa increases (Ladizinsky, 1992). Conversely, success in intergeneric hybridization can sometimes be attributed to taxonomic anomalies rather than the sexual union of very distant parents. Such is the case with citrus relatives where reported "intergeneric" hybrids involving Poncirus Raf., Microcitrus Swing., Eremocitrus Swing., Fortunella Swing., and Citrus (e.g., Barrett, 1977; Hutchison, 1976; Iwamasa et al., $1985,1988)$ would constitute only "interspecific" hybrids under a more conservative taxonomic treatment supported by many recent molecular studies such as Bayer et al. (2009). This molecular evidence reaffirms Citrus [broad circumscription combining all six genera of "true citrus fruit trees" (Swingle and Reece, 1967)] and Citropsis as distinct genera. Considered within the context of this broad circumscription of Citrus, there have been only two successful attempts at intergeneric sexual hybridization within Aurantioideae: the work of Hisato Kunitake and colleagues with Citrus and Citropsis, described previously, and the often overlooked success of Medina et al. (1998) in hybridizing Citrus and Severinia Ten. ex Endl. (syn. Atalantia Corrêa). Both programs have resulted in only small numbers of hybrids with no reported flowering.

Although Citropsis has been little studied, certain species are known to posses traits of potential value to modern citriculture (Krueger and Navarro, 2007) including resistance to burrowing nematode [Radopholus citrophilus Huettel, Dickson \& Kaplan (Ford and Feder, 1960)] and foot rot [Phytophthora nicotianae Breda de Haan (Swingle and Reece, 1967)]. It was one of the better performing citrus relatives in the extensive rootstock work of Bitters et al. (1977) in California but fell short of expectations in Florida because of too many unfavorable 
attributes (Barrett, 1977) including cold tenderness and bud union incompatibility (Ford and Peder, 1969). In our own rootstock experiments in subtropical Australia, 10-year-old 'Eureka' lemon [Citrus limon (L.) Burm. f.] on Citropsis schweinfurthii (Engl.) Swing. \& M.Kell. and Citropsis gilletiana are healthy compact trees surviving under high Phytophthora de Bary pressure. Recognizing that Citropsis species fall short of commercial acceptability in their own right, some breeders have used protoplast fusion in an attempt to capture their useful traits by combining them with complementary Citrus species for use as rootstocks (Grosser and Chandler, 2003; Grosser et al., 1990).

Despite these past efforts, a breeding methodology for the efficient introgression of useful traits from Citropsis without the transfer of economically undesirable characteristics has yet to be demonstrated. To address this problem, we used diverse germplasm in an attempt to efficiently generate fruitful intergeneric hybrids. Siblings of species within the Citrus and Citropsis genera were control-crossed and we report the outcomes here.

\section{Materials and Methods}

Parental material AND hybridization. Two accessions of Citrus wakonai [09Q005 and 09Q006 (seedlings derived from the same fruit collected in the wild on the 8 Sept. 2000)] and two of Citropsis gabunensis \{09Q064 and 09Q065 [seedlings derived from a single tree of PI 246335 at U.S. Department of Agriculture, Agricultural Research Service (USDA-ARS), Riverside, CA, collected on the 27 Apr. 2001]\} were used to generate hybrids. All four accessions were grown from seed at Bundaberg Research Station, Queensland, Australia, with mature plants on their own roots then used for the pollinations. Citrus wakonai possesses a number of traits that made it a desirable choice for this study including: the shortest juvenile period of any known Citrus species; a short fruit maturity time; continuous flowering throughout the year; high seed numbers; monoembryonic seed; and ready-crossability with a range of species (Forster and Smith, 2010). In foliage morphology it is superficially similar to Citrus warburgiana F.M.Bailey [syn. Microcitrus warburgiana (F.M.Bailey) Swing.], although in stature and breeding behavior, it is more like Citrus wintersii Mabb. (syn. Microcitrus papuana H.Winters). It is severely affected by tristeza disease (Citrus tristeza virus family Closteroviridae, genus Closterovirus) making it unsuitable as a rootstock in its own right. Citropsis gabunensis was used exclusively as a male parent because this species yields only one to four seeds per fruit compared with Citrus wakonai, which often exceeds 40 seeds per fruit (Forster and Smith, 2010). Anthers were collected from unopened flowers, allowed to dehisce over silica gel, and the pollen stored at $4{ }^{\circ} \mathrm{C}$ until required. Flowers of the female parent were emasculated before petal opening and immediately pollinated using a camel hair brush.

SeEd haRVEST AND Germination. Fruit resulting from pollinations were collected when they abscised (fully mature), weighed, and seed extracted and dried at room temperature for $12 \mathrm{~h}$. The testa was removed and the seed sown in pasteurized potting mix and kept in an enclosed nursery $\left(16-32^{\circ} \mathrm{C}\right)$ subject to standard citrus nursery practices. After six months' growth, the surviving seedlings were transplanted into individual 5-L pots and retained in the enclosed nursery for observation.

Hybrid observation AND CONFiRmation. Plants were assessed weekly for the presence of flowers. Recurrence of flowering and presence of pollen on anthers were assessed. After 25 months' growth, plants were classified into five categories based on survival and vigor (i.e., recently dead, stunted, small, moderate, vigorous) and the number of flowering hybrids in each family recorded.

Morphological features such as the presence of multiple leaflets, twin thorns, and axillary flower panicles were observed to confirm hybrid status. Leaf extracts from parents and putative hybrids were also subject to isozyme analysis using the well-established PGM enzyme system to score heritable bands for both PGM-1 and PGM-2 (e.g., Grosser et al., 1990). A biomedical cellulose acetate system (Helena Laboratories, Beaumont, TX) was used to enable fast run times (15 min) and sharp band separation.

Statistical analysis was used to examine the breeding behavior of the four individual parent trees with inference restricted to these individuals. Continuous variables such as fruit weight were analyzed using an analysis of variance, examining the factorial combination of female parent and male parent. Percentage data such as fruit set were analyzed using logistic regression and the distribution of seedlings for different vigor categories (based on plant height) were compared using an ordinal regression, also examining the factorial combination of female parent and male parent.

Herbarium voucher specimens of the four parents and the two fruiting intergeneric hybrids (12Q031 and 12Q032) have been lodged with the Queensland Herbarium (BRI).

\section{Results}

Pollinations occurred over a 2-week period in Oct. 2009 with fruit maturing $\approx 15$ weeks later. Results in Table 1 illustrate the relative ease with which intergeneric hybrid seed was generated for these parental combinations. Fruit set rates were high $(29 \%$ to $56 \%$ ) and seed content averaged 30 seeds per fruit, of which over $90 \%$ germinated. Fruit size from intergeneric pollinations was only approximately half that obtained from sib-mating Citrus wakonai, which may explain why fruit maturity time was $\approx 10 \mathrm{~d}$ shorter. Although large numbers of seeds were obtained from the intergeneric crosses, these weighed only $44 \mathrm{mg} / \mathrm{seed}$ compared with $91 \mathrm{mg} / \mathrm{seed}$ for sib-mated Citrus wakonai. Seed yield per fruit was higher for 09Q005 than 09Q006 but was unaffected by the male parent. However, the better fruit set rate of 09Q006 resulted in similar seed yields per pollination performed ( $\approx 11$ seeds per pollination).

High rates of seedling death occurred during the first six months of growth but 327 hybrids remained after 25 months (Table 2). These surviving hybrids showed a wide range of vigor across the four different families (Table 3). The male parent had a significant impact on seedling survival, vigor, and flowering. When 09Q064 was used as a male parent, the percentage of seeds that survived beyond six months was $57 \%$ with 09Q005 and 70\% with 09Q006, but when 09Q065 was the male parent, these survival rates were only $23 \%$ and $37 \%$, respectively. Similarly, 09Q064 parentage resulted in higher rates of early flowering (12.7\% and 1.7\%) compared with 09Q065 $(2.8 \%$ and $0 \%)$. Furthermore, of the plants that survived beyond 6 months, those with 09Q064 parentage were more likely to be vigorous (40\% and $49 \%$ ) than those from 09Q065 (28\% and 27\%). The different female parents had only a minor affect on seedling survival and vigor but dramatically affected the percentage of seedlings that flowered at a young 
Table 1. Fruit and seed development after intergeneric crosses between Citrus wakonai and Citropsis gabunensis using two sibling accessions of each genus. $^{\mathrm{z}}$

\begin{tabular}{|c|c|c|c|c|c|c|c|c|}
\hline \multicolumn{2}{|c|}{$\operatorname{Cross}^{\mathrm{y}}$} & \multirow{2}{*}{$\begin{array}{c}\text { Flowers } \\
\text { pollinated (no.) }\end{array}$} & \multirow{2}{*}{$\begin{array}{c}\text { Fruit } \\
\text { set }(\%)^{x}\end{array}$} & \multirow{2}{*}{$\begin{array}{l}\text { Fruit } \\
\text { wt (g) }\end{array}$} & \multirow{2}{*}{$\begin{array}{l}\text { Maturity } \\
\text { time (d) }\end{array}$} & \multirow{2}{*}{$\begin{array}{l}\text { Seeds per } \\
\text { fruit (no.) }\end{array}$} & \multirow{2}{*}{$\begin{array}{c}\text { Seeds per } \\
\text { pollination (no.) }\end{array}$} & \multirow{2}{*}{$\begin{array}{c}\text { Seed } \\
\text { germination }(\%)\end{array}$} \\
\hline Female & Male & & & & & & & \\
\hline $09 \mathrm{Q} 005(\mathrm{Cw})$ & 09Q064(Cg) & 17 & 29 & 28 & 108 & 32 & 9 & 94 \\
\hline 09Q005(Cw) & 09Q065(Cg) & 45 & 31 & 26 & 105 & 36 & 11 & 97 \\
\hline 09Q006(Cw) & 09Q065(Cg) & 16 & 50 & 21 & 103 & 22 & 11 & 94 \\
\hline \multicolumn{3}{|c|}{ Significance, female $P$} & 0.066 & 0.248 & 0.029 & 0.008 & 0.394 & 0.089 \\
\hline \multicolumn{3}{|c|}{ Significance, male $P$} & 0.832 & 0.617 & 0.467 & 0.567 & 0.751 & 0.078 \\
\hline
\end{tabular}

${ }^{\mathrm{z}}$ Sib-mated Citrus wakonai results included for comparison.

${ }^{\mathrm{y}} \mathrm{Cw}=$ Citrus wakonai; $\mathrm{Cg}=$ Citropsis gabunensis .

${ }^{\mathrm{x}}($ no. mature fruit harvested/no. flowers pollinated $) \times 100$.

Table 2. Seedling emergence, survival, and flowering of intergeneric hybrids between Citrus wakonai and Citropsis gabunensis using two sibling accessions of each genus.

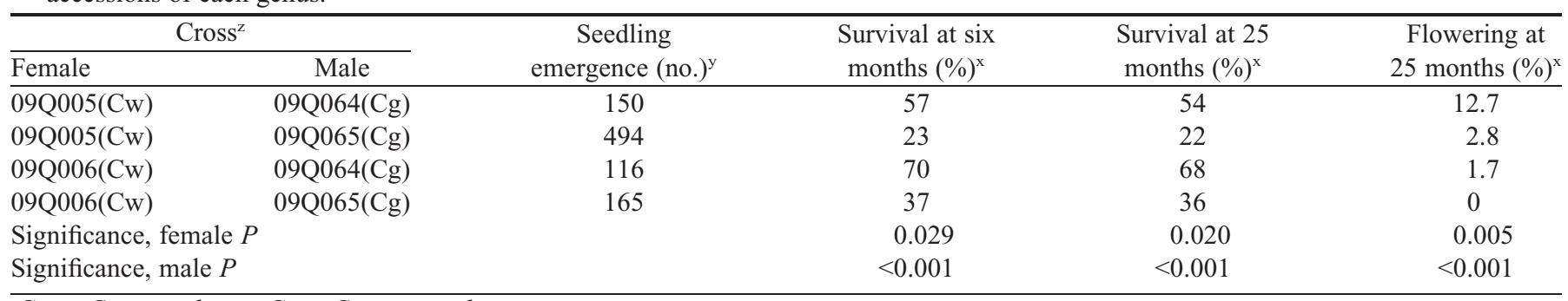

${ }^{\mathrm{z}} \mathrm{Cw}=$ Citrus wakonai; $\mathrm{Cg}=$ Citropsis gabunensis.

${ }^{y}$ Emergence measured 4 weeks after sowing.

${ }^{x}$ Based on the number of seedlings that emerged.

Table 3. Vigor of surviving hybrids between Citrus wakonai and Citropsis gabunensis at 25 months of age.

\begin{tabular}{|c|c|c|c|c|c|c|c|}
\hline \multirow{2}{*}{\multicolumn{2}{|c|}{ Cross $^{\mathrm{z}}$}} & \multirow{3}{*}{$\begin{array}{c}\text { Plants in } \\
\text { family (no.) }\end{array}$} & \multicolumn{5}{|c|}{ Percent of family falling into five vigor categories (\%) } \\
\hline & & & \multirow{2}{*}{$\begin{array}{c}\text { Recently } \\
\text { dead }\end{array}$} & \multirow{2}{*}{$\begin{array}{c}\text { Stunted } \\
(\text { Less than } 30 \mathrm{~cm})\end{array}$} & \multirow{2}{*}{$\begin{array}{c}\text { Small } \\
(30-50 \mathrm{~cm})\end{array}$} & \multirow{2}{*}{$\begin{array}{c}\text { Moderate } \\
(50-100 \mathrm{~cm})\end{array}$} & \multirow{2}{*}{$\begin{array}{c}\text { Vigorous } \\
(\text { Greater than } 100 \mathrm{~cm})\end{array}$} \\
\hline Female & Male & & & & & & \\
\hline 09Q005(Cw) & 09Q064(Cg) & 81 & 2 & 5 & 19 & 35 & 40 \\
\hline 09Q006(Cw) & 09Q064(Cg) & 79 & 3 & 11 & 18 & 19 & 49 \\
\hline 09Q006(Cw) & 09Q065(Cg) & 59 & 0 & 20 & 32 & 20 & 27 \\
\hline
\end{tabular}

${ }^{\mathrm{z}} \mathrm{CW}=$ Citrus wakonai; $\mathrm{Cg}=$ Citropsis gabunensis .

${ }^{y}$ Low values caused convergence to fail; hence, no analysis available.

age. When $09 \mathrm{Q} 005$ was used as a female parent, $12.7 \%$ of hybrids with 09Q064 and $2.8 \%$ of hybrids with $09 \mathrm{Q} 065$ had flowered within 25 months compared with 09Q006 in which the percentages were only $1.7 \%$ and $0 \%$, respectively.

Hybrid seedlings were readily identified even at a young age by their morphology (Fig. 1A). Most notably, they had trifoliate leaves and paired axillary spines. The female parent Citrus wakonai has unifoliate leaves and before these pollinations, its progeny have only ever produced trifoliate leaves when crossed with Poncirus or Poncirus hybrids. The trifoliate leaf form is consistent with the intergeneric sexual hybrids shown in Yahata et al. (2006) and somatic hybrids in Grosser et al. (1990). All hybrids produced unifoliate leaves during their first three months of growth after which leaf form changed to trifoliate. Subsequent leaves were unifoliate, bifoliate, or trifoliate in no particular order and varying widely between individual hybrids. There were never more than three leaflets. Similarly, most hybrids had some paired axillary spines, although these were interspersed with single spines. The only other known heritable source of multiple spines is Citrus inodora F.M.Bailey (Bowman, 1998). All flowering hybrids had multiple flower buds (2-12) on axillary panicles, a trait clearly inherited from their Citropsis parent. Table 4 shows key states of expression for parents and the two fruiting hybrids.

The PGM enzyme system proved a fast and convenient means to confirm hybridity (Fig. 2). Both accessions of both parents were homozygous at PGM-1 and PGM-2, consistent with their species status. Moreover, allele sizes were distinctly different between the two genera making it possible to readily identify each allele in its heterozygous state in hybrids. Interestingly, one of the accessions of Citropsis gabunensis (09Q064) carried a null allele for PGM-1, which was inherited in its progeny, thus making it possible to confirm not only hybrid status, but also which of the two Citropsis parents was involved. 


\section{Discussion}

Until recently, Citrus and Citropsis were considered sexually incompatible based on unsuccessful attempts by many breeders over the last 100 years to make this cross. Even the recent success (Yahata et al., 2006; Yasuda et al., 2010) has required special techniques like in vitro germination and grafting and has resulted in only a handful of hybrids with poor growth and no flowering. Despite this, we have easily obtained a large population of vigorous hybrids using conventional hybridization and standard nursery techniques. Thirtyseven of these intergeneric hybrids have flowered at little more than two years of age, and two of them have set fruit. Prospects for the introgression of Citropsis genes into modern citriculture through conventional breeding have greatly improved.

Sudden advances of similar magnitude have occurred in intergeneric breeding with other crops such as sugarcane in which decades of attempts to introgress Erianthus Michx. with Saccharum L. met with failure or at best the occasional sterile hybrid (Cheng et al., 2003). Persistent efforts by Chinese breeders and their inclusion of diverse accessions eventually resulted in hybrids with limited fertility, which were then improved through manipulation of flowering time and backcrossing (Wang et al., 2007). We believe that our success in hybridizing Citrus and Citropsis is likewise attributable to the broad range of germplasm used in our hybridization program.

To date, all 37 of our flowering hybrids appear to be pollen-sterile, although more observations under different temperatures and on older plants are required to confirm this.

Fig. 1. Morphology of the intergeneric hybrids 12Q031 and 12Q032, resulting from a cross between Citrus wakonai and Citropsis gabunensis. (A) Fruiting branch of 12Q031 with recurrent production of flower panicles. Trifoliate and bifoliate leaves indicated by $\leftarrow$; (B) external fruit appearance of Citrus wakonai (left), 12Q031 (center top), 12Q032 (center bottom) and Citropsis gabunensis (right); (C) internal fruit appearance of Citrus wakonai (left), 12Q031 (center top), 12Q032 (center bottom), and Citropsis gabunensis (right).

Table 4. States of expression of some key morphological characteristics of Citrus $\times$ Citropsis intergeneric hybrids and their parents.

\begin{tabular}{|c|c|c|c|c|}
\hline \multirow[b]{2}{*}{ Character } & \multicolumn{2}{|c|}{ Parents } & \multicolumn{2}{|c|}{ Intergeneric hybrids } \\
\hline & Citrus wakonai & Citropsis gabunensis & 12Q031 & 12Q032 \\
\hline Axillary spines & Solitary & Paired & Sometimes paired & Solitary \\
\hline Leaflet number & Unifoliate & $1-5(-7)$-foliate & 1-3-foliate & 1-3-foliate \\
\hline Petiole length (mm) & $2-5$ & $15-55$ & $6-27$ & $10-22$ \\
\hline Inflorescence & Solitary (2-3 fascicle) & $4-16$ in panicle & $2-10$ in panicle & $3-5$ in panicle \\
\hline Sepals/petals & 5 & 4 & $4(5)$ & 3 \\
\hline Stamens & $18-20$ & 8 & $8-10$ & 6 \\
\hline Filaments & Irregular & Uniform & Uniform & Uniform \\
\hline Pollen & Yellow & White & Absent & Absent \\
\hline Ovary locules & $5(-8)$ & $3-4$ & 5 & 5 \\
\hline Fruit weight (g) & $25-60$ & $3-5$ & $5-10$ & $6-10$ \\
\hline Fruit length (mm) & $44-65$ & $18-22$ & $25-31$ & $24-28$ \\
\hline Juice acid ( $\%$ citric equivalent) & 9.4 & z & 8.7 & 8.4 \\
\hline Seeds & $12-87$ & $1-4$ & 0 & 0 \\
\hline
\end{tabular}

${ }^{\mathrm{z}}$ Sap prevented measurement. 


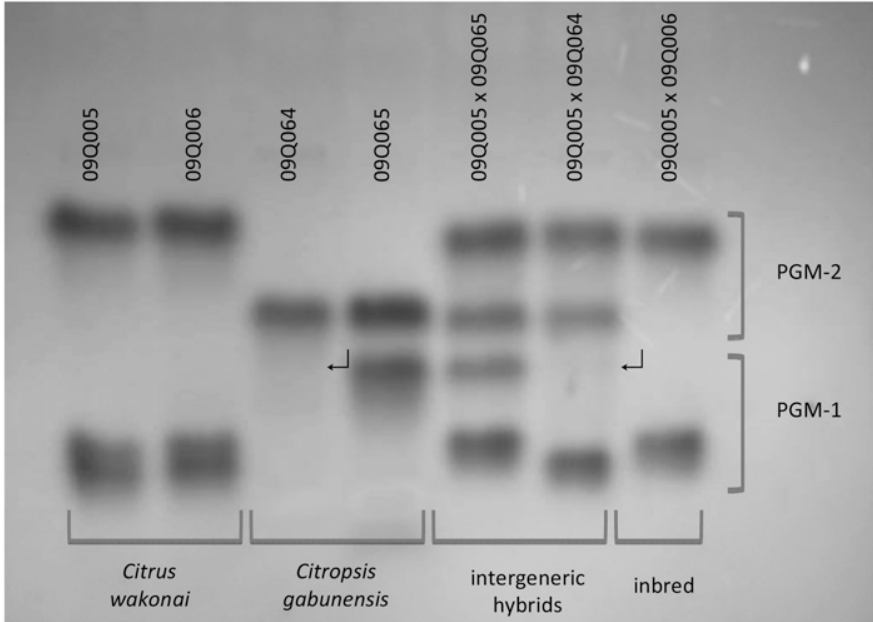

Fig. 2. Banding patterns for two parental accessions of Citrus wakonai and Citropsis gabunensis and their intergeneric hybrids for the enzyme systems PGM-1 and PGM-2. Sib-mated Citrus wakonai shown on the right hand lane. $\checkmark$ indicates null allele.

Although pollen sterility is common in intergeneric crossing and is more conspicuous when the species involved are distantly related, there can be considerable variation between $F_{1}$ plants (Belea, 1992). The ease with which we have hybridized Citrus and Citropsis creates the opportunity to establish a population of hybrids that may be large enough to identify male-fertile segregants.

Female sterility in intergeneric crosses is generally less severe than that of male sterility and there are many examples of cultivated plants in which new genera have been successfully introgressed despite complete pollen sterility in the $F_{1}$. However, breeding beyond the $F_{1}$ often requires large populations because the frequency of individuals with viable embryo sacs is very low. For example, in the much studied Poaceae in which distant genera have been successfully introgressed despite often complete male sterility, useable levels of female fertility have averaged only one plant in 300 for Aegilops L. $\times$ Triticum L., one plant in 1250 for Triticum $\times$ Haynaldia L., and one plant in 1700 for Triticum $\times$ Secale L. hybrids (Belea, 1992). Such large plant numbers present enormous challenges for tree-crop breeders but serve to underline the importance of developing an efficient breeding methodology if distant genera are to contribute to modern citriculture. Moreover, the phenomenon of unilateral incompatibility makes the identification of different individuals that are female-, male-, or female-and-male-fertile important to the continued introgression of Citropsis.

The high rate of seedling death (63\%) during the first six months of growth observed in our Citrus $\times$ Citropsis plants is a common phenomenon in distant hybridization, known as lateacting lethality. For example, the first intergeneric hybrids in coffee breeding between Psilanthus Hook.f. and Coffea L. resulted in 41 plants, but $78 \%$ of these wilted and died during the first five months in the nursery (Couturon et al., 1998). Death occurred in three grafted clones as well as the original seedling for those genotypes affected, supporting the authors' assertion that segregating deleterious genes were the cause. In citrus breeding, Barrett $(1977,1985)$ observed the same problem in crossing Eremocitrus, Fortunella, and Microcitrus with Poncirus. Propagating the hybrid seedlings onto a different root system extended the lifespan but all eventually died. Swingle (1945) had similar difficulty in obtaining long-lived hybrids of Fortunella and Poncirus but had better success when using citranges (Citrus $\times$ Poncirus hybrids) as the pollen parent, illustrating the value of bridging species (Khush and Brar, 1992). Our crosses of Citrus wakonai with Poncirus have shown similar late-acting lethality (Forster and Smith, 2010) including the death of grafted hybrids, although a few longlived individuals have been obtained by generating a large initial population.

The results clearly demonstrate the importance of including a range of accessions when attempting intergeneric crosses. Even in this work, in which the accessions were closely related (half- or full-sibs of good species), the impact on characteristics like fruit set, seedling survival, plant vigor, and propensity to flower were significant. These characteristics are of critical importance in conducting an efficient breeding program to introgress genes from distant taxa, even before the breeding value of individual hybrids has been assessed. Reed et al. (2008) observed the same response in intergeneric crosses for ornamental breeding in which different selections of the same species altered the efficiency with which flowering hybrids were produced. Use of diverse germplasm has also been critical to the success of intergeneric hybridization for food plants, including those from the families Brassicaceae, Cucurbitaceae, Poaceae, and Solanaceae (Belea, 1992). Falk and Kasha (1981) included 42 wheat cultivars (Triticum aestivum L.) in their attempted hybridizations with wild barley (Hordeum bulbosum L.) and obtained zero seed set in 21 of these crosses and less than $10 \%$ set in a further 11 crosses. However, they obtained an acceptable rate of greater than $30 \%$ set with just three of the 42 cultivars tested. Furthermore, there is evidence that varieties with good combining ability in one particular intergeneric cross will also perform well when crosses are performed with other genera. Genetic control of ready-crossability has often been inherited in a simple manner such as a recessive trait controlled by just two loci (Ladizinsky, 1992). Identification of crosscompatible variants of Citrus and Citropsis represents an important opportunity to improve the efficiency of intergeneric breeding as well as expand crossing to more difficult genera and hence extend the wild gene pool available for citrus genetic improvement.

Unfortunately, most citrus germplasm collections throughout the world hold very few accessions of citrus relatives so opportunities for broad-scale screening of cross-compatibility such as the wheat example described previously are limited. Further limiting the genetic diversity of world collections is the fact that many holdings of citrus relatives are duplicates of the same accession supplied from another collection, notably the USDA-ARS/University of California at Riverside, CA. In many instances there is only one accession available for breeding, and indeed there are still some citrus relatives that do not exist in any collection. Although modern authors commonly espouse the importance of germplasm diversity, there have been few recent attempts to collect new accessions, relying instead on material that was mostly brought into cultivation more than 50 years ago. Although well intentioned, the current focus on preserving genetic diversity in situ, and to biodiversity agreements that restrict germplasm exchange between countries, is also hindering the capacity of citrus breeders to develop environmentally sustainable solutions. In the absence of these much needed new collections, generation of segregating seedling populations from 
existing accessions (as with our seedlings of Citropsis gabunensis PI 246335) can create some of the diversity needed to increase the efficiency of intergeneric breeding.

Recent taxonomic attempts to reduce the number of genera within the citrus subfamily Aurantiodeae have also served to reaffirm that Citrus and Citropsis are indeed distinct genera. In the molecular phylogeny of Bayer et al. (2009), all of the former genera of the "true citrus fruit trees" (Swingle and Reece, 1967) fall into a monophyletic clade (Clade Q). The Citropsis species are quite distant from this clade, falling two levels back (Clade N), thus supporting Citropsis as a genus distinct from Citrus. Therefore, even a conservative taxonomic treatment of the Aurantiodeae establishes the material in our work as the most distant intergeneric fruiting hybrids ever produced within this subfamily and possibly within Rutaceae. Maintenance of a high level of residual fertility between these distant taxa has potential evolutionary implications and may point to an African origin of Citrus. Such a proposal draws some support from the rich diversity of Rutaceous fossils now being discovered in Africa including the oldest definitive fossil evidence of the subfamily Aurantiodeae; a Clausena Burm.f. from Ethiopia dated to the Late Oligocene (27.23 Ma) (Pan, 2010). Swingle and Reece (1967) considered that Citropsis arose in Africa after migration from "the southeastern Asiatic homeland," although it now seems possible that migration was in the opposite direction. Scora (1988) struggled with the direction of migration but was constrained by the Asia presence of Micromelum Blume (which was then considered the most primitive aurantioid taxa) to believe it had to be from Asia to Africa. He nonetheless recognized that this "does not sound very convincing" and acknowledged that the existence of uniquely African genera within Aurantiodeae remained a puzzle. Abbo et al. (2001) caution against methods for locating centers of origin that are not corroborated with fossil evidence, of which the inferred Asian origin of Citrus would appear to be a case in point.

Although not always biologically possible, breeding at the diploid level represents the most efficient means of intergeneric gene transfer because undesirable "wild genes" can be quickly eliminated from the population (Hermsen, 1992). Somatic hybrids create the opportunity to combine very distant taxa but they are often unstable and sterile and so of no practical breeding use; they are generally polyploid making them more difficult to backcross and unsuitable for a second round of somatic fusion (Hermsen, 1992). Furthermore, somatic hybridization is an additive process without recombination and segregation (Grosser and Gmitter, 1990b) so genetic diversity and opportunities for selection in the $F_{1}$ are limited. Thus, although citrus somatic hybrids were initially seen as overcoming the problems of conventional intergeneric crossing (Grosser and Gmitter, 1990a), only limited progress has been made beyond the initial fusion products. Indeed, most somatic hybrids between Citrus (broad circumscription) and related genera have yet to flower despite their considerable age, possibly as a result of somatic incompatibility (Guo and Deng, 2001), and although somatic hybridization is still being used for rootstock breeding, emphasis has shifted to its use in breeding seedless fruit (Grosser and Gmitter, 2011).

Our work demonstrates that there are still significant advances to be made through conventional hybridization. The identification of accessions with high crossability and development of methodologies for the efficient generation of large populations to compensate for late-acting lethality and low fertility may create the opportunity to introgress whole new genera previously considered inaccessible. The 37 flowering hybrids are being maintained and monitored for evidence of male and/or female fertility, which would enable further breeding. However, experience from other cultivated plants suggests that a far larger $F_{1}$ population is required to identify fertile segregants, and so new hybrids of 09 Q $005 \times 09$ Q 064 are being generated. These will be established under field conditions within a mixed Citrus collection to maximize opportunities for cross-pollination and subsequent development of any viable embryo sacs. A sample of 19 non-flowering intergeneric hybrids has already been established in the field to test the adaptation of seedlings on their own roots. Furthermore, clonal material of the two fruiting intergeneric hybrids (12Q031 and 12Q032) has been readily generated from single-node cuttings and will soon be budded and tested alongside commercial rootstocks. Although this clonal $\mathrm{F}_{1}$ material may be of some value, we consider that the best prospects for contributing to modern citriculture will come with the discovery of sufficient fertility to allow breeding beyond the $F_{1}$. Thus, having established a methodology for the efficient generation of flowering/fruiting diploid hybrids between Citrus and Citropsis, our practical efforts will now focus on developing hybrid populations that are sufficiently large enough to enable the identification of fertile segregants for further breeding.

\section{Literature Cited}

Abbo, S., S. Lev-Yadun, and G. Ladizinsky. 2001. Tracing the wild genetic stocks of crop plants. Genome 44:309-310.

Barrett, H.C. 1977. Intergeneric hybridization of Citrus and other genera in citrus cultivar improvement. Proc. 3rd Intl. Citrus Congr. p. 586-589.

Barrett, H.C. 1985. Hybridization of Citrus and related genera. Fruit Var. J. 39:11-16.

Bayer, R.J., D.J. Mabberley, C. Morton, C.H. Miller, I.K. Sharma, B.E. Pfeil, S. Rich, R. Hitchcock, and S. Sykes. 2009. A molecular phylogeny of the orange subfamily (Rutaceae: Aurantioideae) using nine cpDNA sequences. Amer. J. Bot. 96:668-685.

Belea, A. 1992. Interspecific and intergeneric crosses in cultivated plants. Akadémiai Kiadó, Budapest, Hungary.

Bitters, W.P., D.A. Cole, and C.D. McCarthy. 1977. Citrus relatives are not irrelevant as dwarfing stocks or interstocks for citrus. Proc. 3rd Intl. Citrus Congr. p. 561-567.

Bowman, K.D. 1998. Segregation for double spine trait in hybrids of Microcitrus inodora. HortScience 33:473.

Cheng, F., D. Haihua, and C. Xiwen. 2003. Research and utilization of Erianthus arundinaceus at Hainan Sugarcane Breeding Station. Sugarcane Canesugar 6:1-14.

Cooper, W.C., P.C. Reece, and J.R. Furr. 1962. Citrus breeding in Florida - Past, present and future. Proc. Florida State Hort. Soc. 75:5-13. Couturon, E., P. Lashermes, and A. Charrier. 1998. First intergeneric hybrids (Psilanthus ebracteolatus Hiern $\times$ Coffea arabica L.) in coffee trees. Can. J. Bot. 76:542-546.

Falk, D.E. and K.J. Kasha. 1981. Comparison of the crossability of rye (Secale cereale) and Hordeum bulbosum onto wheat (Triticum aestivum). Can. J. Genet. Cytol. 23:81-88.

Ford, H.W. and W.A. Feder. 1960. Citropsis gilletiana, a citrus relative resistant to the burrowing nematode in laboratory tests. Proc. Florida State Hort. Soc. 73:60-64.

Ford, H.W. and W.A. Peder. 1969. Development and use of citrus rootstocks resistant to the burrowing nematode, Radopholus similis. Proc. 1st Intl. Citrus Congr. p. 941-948.

Forster, P.I. and M.W. Smith. 2010. Citrus wakonai P.I.Forst.\&M.W.Sm. (Rutaceae), a new species from Goodenough Island, Papua New Guinea. Austrobaileya 8:133-138.

Grosser, J.W. and J.L. Chandler. 2003. New citrus rootstocks via protoplast fusion. Acta Hort. 622:491-497. 
Grosser, J.W. and F.G. Gmitter, Jr. 1990a. Protoplast fusion and citrus improvement. Plant Breed. Rev. 8:339-374.

Grosser, J.W. and F.G. Gmitter, Jr. 1990b. Somatic hybridization of Citrus with wild relatives for germplasm enhancement and cultivar development. HortScience 25:147-151.

Grosser, J.W. and F.G. Gmitter. 2011. Protoplast fusion for production of tetraploids and triploids: Applications for scion and rootstock breeding in citrus. Plant Cell Tissue Organ Cult. 104:343-357.

Grosser, J.W., F.G. Gmitter, Jr., N. Tusa, and J.L. Chandler. 1990. Somatic hybrid plants from sexually incompatible woody species: Citrus reticulata and Citropsis gilletiana. Plant Cell Rep. 8:656659.

Grosser, J.W., F.A.A. Mourao-Fo, F.G. Gmitter, Jr., E.S. Louzada, J. Jiang, K. Baergen, A. Quiros, C. Cabasson, J.L. Schell, and J.L. Chandler. 1996. Allotetraploid hybrids between Citrus and seven related genera produced by somatic hybridization. Theor. Appl. Genet. 92:577-582.

Guo, W.W. and X.X. Deng. 2001. Wide somatic hybrids of Citrus with its related genera and their potential in genetic improvement. Euphytica 118:175-183.

Hermsen, J.G.T. 1992. Introductory considerations on distant hybridization, p. 1-14. In: Kalloo, G. and J.B. Chowdhury (eds.). Distant hybridization of crop plants. Springer-Verlag, Berlin, Germany.

Hutchison, D.J. 1976. Interspecific hybridization in Citrus rootstocks. Fruit Var. J. 30:34

Iwamasa, M., N. Nito, Y. Katayama, T. Yamaguchi, and S. Matsunaga. 1985. Cross compatibility between plants of the Aurantioideae. Bul. Faculty Agr. Saga Univ. 59:57-69.

Iwamasa, M., N. Nito, and J.T. Ling. 1988. Intra- and intergeneric hybridization in the orange subfamily, Aurantioideae. Proc. 6th Intl. Citrus Congr. p. 123-130.

Khush, G.S. and D.S. Brar. 1992. Overcoming the barriers in hybridization, p. 47-61. In: Kalloo, G. and J.B. Chowdhury (eds.). Distant hybridization in crop plants. Springer-Verlag, Berlin, Germany.

Krueger, R.R. and L. Navarro. 2007. Citrus germplasm resources, p. 45-140. In: Khan, I.A. (ed.). Citrus genetics, breeding and biotechnology. CABI, Wallingford, UK.
Ladizinsky, G. 1992. Crossability relations, p. 15-31. In: Kalloo, G. and J.B. Chowdhury (eds.). Distant hybridization in crop plants. Springer-Verlag, Berlin, Germany.

Medina, F.-H.P., R. Bordignon, and R.M.L. Ballve. 1998. Sunkifolias and Buxisunkis: Sexually obtained reciprocal hybrids of Citrus sunki $\times$ Severinia buxifolia. Genet. Mol. Biol. 21:129-133.

Pan, A.D. 2010. Rutaceae leaf fossils from the Late Oligocene (27.23 Ma) Guang River flora of northwestern Ethiopia. Rev. Palaeobot. Palynol. 159:188-194.

Reed, S.M., K.D. Jones, and T.A. Rinehart. 2008. Production and characterization of intergeneric hybrids between Dichroa febrifuga and Hydrangea macrophylla. J. Amer. Soc. Hort. Sci. 133:84-91.

Scora, R.W. 1988. Biochemistry, taxonomy and evolution of modern cultivated citrus. Proc. 6th Intl. Citrus Congr. p. 277-289.

Swingle, W.T. 1913. New citrous fruits. Amer. Breeders Mag. 4:83-95. Swingle, W.T. 1914. Citropsis, a new tropical African genus allied to Citrus. J. Agric. Res. 1:419-437.

Swingle, W.T. 1945. New disease-resistant rootstocks urgently needed by citrus growers. Proc. Florida State Hort. Soc. 58:201-205.

Swingle, W.T. and P.C. Reece. 1967. The botany of citrus and its wild relatives, p. 190-430. In: Reuther, W., H.J. Webber, and L.D. Batchelor (eds.). The citrus industry: Vol. 1. History, world distribution, botany and varieties. Univ. of California, Berkeley, CA.

Tasker, G. 2010. Walter Swingle, citrus legend. Trop. Garden Winter:24-27.

Wang, L., Q. Cai, Y. Fan, X. Lu, K. Aitken, L. Ma, X. Liu, and H. Xia. 2007. Study on the distant hybrid utilization between Saccharum and Erianthus arundinanceus. Southwest China J. Agr. Sci. 20:721726

Yahata, M., H. Kunitake, K. Yasuda, K. Yamashita, H. Komatsu, and R. Matsumoto. 2006. Production of sexual hybrid progenies for clarifying the phylogenic relationship between Citrus and Citropsis species. J. Amer. Soc. Hort. Sci. 131:764-769.

Yasuda, K., H. Kunitake, M. Yahata, and R. Matsumoto. 2010. Investigation of sexual intergeneric hybrid progenies between citrus cultivars and Citropsis schweinfurthii. Proc. 11th Intl. Citrus Congr. p. $121-124$. 